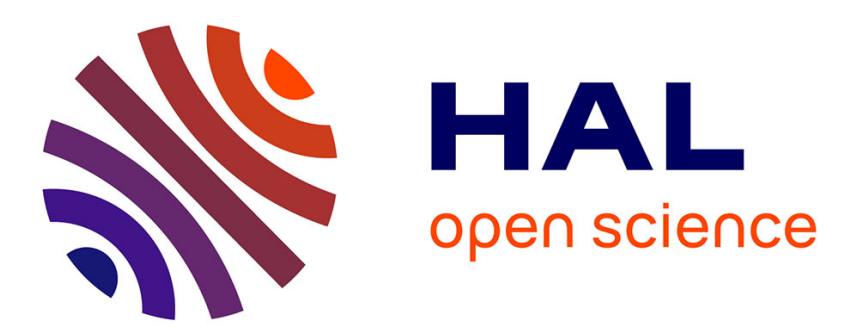

\title{
A novel method for the sustainable management of wheat crops: exploration by simulation
}

Marie-Hélène Chatelin, Christine Aubry, Frederick Garcia

\section{To cite this version:}

Marie-Hélène Chatelin, Christine Aubry, Frederick Garcia. A novel method for the sustainable management of wheat crops: exploration by simulation. Agronomy for Sustainable Development, 2007, 27 (4), pp.337-345. 10.1051/agro:2007014 . hal-01197705

\section{HAL Id: hal-01197705 \\ https://hal.science/hal-01197705}

Submitted on 30 May 2020

HAL is a multi-disciplinary open access archive for the deposit and dissemination of scientific research documents, whether they are published or not. The documents may come from teaching and research institutions in France or abroad, or from public or private research centers.
L'archive ouverte pluridisciplinaire HAL, est destinée au dépôt et à la diffusion de documents scientifiques de niveau recherche, publiés ou non, émanant des établissements d'enseignement et de recherche français ou étrangers, des laboratoires publics ou privés. 


\title{
A novel method for the sustainable management of wheat crops: exploration by simulation
}

\author{
M.-H. ChATELIN ${ }^{\mathrm{a}}$, C. AUBRY $^{\mathrm{b} *}$, F. GARCIA $^{\mathrm{c}}$ \\ ${ }^{\text {a }}$ INRA/ESR, 65 Bd de Brandebourg, 94205 Ivry sur Seine Cedex, France \\ b INRA SADAPT, 16 rue Claude Bernard, 75231 Paris Cedex 05, France \\ c INRA BIA, BP 52627, Auzeville, 31326 Castanet Tolosan Cedex, France
}

(Accepted 2 April 2007)

\begin{abstract}
Designing crop management strategies to meet both environmental and economic objectives is a growing preoccupation for advisers and researchers, in the move towards sustainable development. We describe here a simple and original method designed to facilitate this task and appropriate field experimentation. This method involves the use of a multi-stage procedure in which a simulation tool is used to explore a decisional space defined by an expert. As a case study, we designed crop management strategies for winter wheat in the Paris Basin. We aimed to maintain a high wheat yield of more than 9 t.ha $^{-1}$ and grain quality whilst limiting the risks of nitrogen pollution by maintaining post-harvest soil nitrogen content below $30 \mathrm{~kg} \cdot \mathrm{ha}^{-1}$. The method was applied on two representative field situations with contrasting soil nitrogen supplies. We used the "DéciBlé" simulation tool to evaluate management strategies, expressed as sets of decision rules, for the possible technical choices such as cultivar, sowing date, sowing density and nitrogen supply. Our step-by-step approach involved progressive limitation of the decisional domain to be explored, and some of the solutions obtained were not intuitive. This method has two main novel features: (1) a simple design dealing with a complex problem, without reduction to a single judgement criterion and (2) results expressed as action plans similar to those implemented by farmers.
\end{abstract}

crop model / simulation / decision support system / winter wheat / exploration

\section{INTRODUCTION}

The demands of technical farm management have increased in complexity in developed countries, with farm products now required to fit into a particular market sector or to satisfy environmental objectives, such as the prevention of nitrate pollution and erosion. Farmers are also encouraged to review and diversify their cultural techniques, necessitating the design by advisors and researchers of new technical management models for crops rather than the simple provision of day-to-day advice for each operation. This requires the building of action plans for farmers - technical decision rules for the whole crop cycle - the domain of crop strategic planning, as described by McCown (2002). The design of appropriate technical management models is neither trivial nor intuitive when the aim is to meet the production and environmental objectives simultaneously required. Here is a simple illustration:

How can fundamentally opposite objects, such as limiting the nitrate concentration of the water leaving a wheat field whilst maintaining high wheat yield and grain protein content, be reconciled? The first of these objectives is necessary to ensure that the legal maximum nitrate concentration for drinking water $\left(50 \mathrm{mg} . \mathrm{L}^{-1}\right)$ is not exceeded, whereas the second is a baking quality criterion used by wheat buyers, requiring nonlimiting nitrogen nutrition of the crop. How can these com-

* Corresponding author: caubry@inapg.inra.fr plex environmental and economic objectives be transformed into concrete technical wheat action plans for the farmer?

Classical experimentation might provide the solution, but would require a huge number of factorial trials to combine all the cultural techniques in use (see below) over a sufficiently large range of soil and weather conditions. This would be prohibitive in terms of both the time and resources required.

The use of models for simulating technical crop management appears to be more appropriate for this purpose. This recently developed approach is rapidly advancing (Cox, 1996; Jones et al., 2003; Keating et al., 2003). For example, wheat crops for bioethanol production must meet several objectives, including profit margins, energy balance and the limitation of certain agronomic risks. A method combining the use of a biotechnical simulator, BETHA, with a multi-criteria analysis of the results of the simulation has been designed to guide technical management (Loyce et al., 2002). This method selects combinations of prediction options for each cultural operation considered, some of which are very extensive, and these options are tested by field experimentation. However, these new solutions are difficult to translate into real action plans for a farmer because they are not expressed in the form of decision rules for technical management.

Work is currently underway to model the interaction between the cropping system and the farmer managing this system (Chatelin et al., 1993; Hammer et al., 2002; McCown, 2002; Chatelin et al., 2005). The farmer's behaviour is 
generally modelled in terms of decision rules enabling him to adapt his technical choices to the risks encountered (essentially weather). The application of such models to the resolution of decisional problems such as that described above has been the subject of only a few studies, such as that of Gibbons et al. (2005). At least one well-known study, the FARMSCAPE study in Australia (Carberry et al., 2002), has used simulation models as part of a decision support intervention programme for farmers and advisers.

We present here an original, simple method involving the use of a multi-stage procedure to explore a complex simulation model with the aim of designing technical crop management strategies and appropriate field experiments. We studied the case of winter wheat management to meet the two objectives cited in the introduction. We used the DéciBlé simulation tool to simulate management strategies as sets of decision rules for cropping techniques and to evaluate the effect of the chosen techniques on wheat yield and environment quality. DeciBlé was designed for use by researchers and advisers, but not directly by farmers: the aim is to help these experts to explore ranges of technical strategies and to prepare future experiments or to guide them in the advice they issue to farmers (see Chatelin et al., 2005).

We propose an approach based on the systematic exploration of a decisional space defined by an expert. This decisional space represents the set of possible strategies for managing the crop, described as decision rules for all the cropping practices involved. The expert is an agronomist (researcher or adviser) who determines the decisional space to be explored for a given problem. The expert then uses DeciBlé for experiment simulations (design of action plans) and evaluates the results of the simulations according to predetermined criteria.

We first present the concept and principles of DéciBlé, formalisation of the problem and the choice of typical situations. We then describe how we defined the decisional space to be explored and how we used DéciBlé to explore the possible solutions within this decisional space. Based on these simulations, technical management strategies are then proposed. Finally, we discuss the results obtained and the potential role of this exploration technique, together with other methods, in the design of technical management strategies.

\section{MATERIALS AND METHODS}

\subsection{The DeciBlé simulation tool: concepts and functioning}

DéciBlé proposes methods for designing and evaluating strategies for technical wheat management based on "experimenting with the model" (Quéau, 1986; Attonaty et al., 1999). Based on work on technical decision-making in arable farming (Chatelin et al., 1993; Papy, 1994; Aubry et al., 1998), management strategies are designed in terms of objectives, decision rules and appropriate usable indicators. These strategies are therefore intended to serve as "a set of planned tasks that incorporates provisions to adapt to stochastic fluctuation of the environment (the weather in particular)" (Cros et al., 2004).
As suggested by Lorino (1991), strategies are accompanied by user-built performance criteria, making diagnosis possible.

DéciBlé is used to evaluate and compare sets of decision rules in a chosen range of field and weather situations, in terms of both the actions taken in each scenario and their consequences for the wheat performance criteria (technical, economic, environmental) defined by the user.

DéciBlé is thus designed to be run on a day-to-day basis in a predefined field, with a parallel weather database, a crop model for winter wheat and a decisional model containing the decision rules (Fig. 1). The first two of these elements provide the state variables used as indicators for decision-making and for implementing technical actions that will, in turn, modify the state of the system simulated. The results for each weather scenario are expressed as a function of the criteria chosen by the user. Each part of Figure 1 is explained in brief below.

The weather database provides data for daily temperature, precipitation, radiation and potential evapotranspiration. This database may include real meteorological data for the chosen region - the last 20 years in our case - or data generated by a random weather generator. The field is initially characterised in terms of its soil type and cropping history. The decision rules model includes the rules chosen by users based on their objectives and strategy. The current version of DéciBlé includes decision rules for sowing and nitrogen application only. It determines the technical actions to be taken: cultivar, sowing density and soil preparation, rates and dates of $\mathrm{N}$ applications, depending on the weather, the state of the crop (see below) and the field. For each scenario (weather, field, techniques), the crop model simulates the development of the crop and yield components at key stages for decision-making. For example, information about the number of plants at the end of winter is useful for decisions concerning the first nitrogen application, whereas biomass at the $1-\mathrm{cm}$ ear stage provides the key information for decisions concerning the second nitrogen application. DéciBlé also simulates the final state of the field, in terms of water balance and the structure of the arable layer. The construction of the decisional model required the development of a specific language, with a glossary and a grammar. This language uses conditional structures (IF, AS SOON AS, AS LONG AS) as indicators of the state of the simulated system (weather, plant) and the technical decisions taken into account by the biotechnical model.

The three elements of the model are linked by a simulation engine running on a day-to-day basis, interpreting the decision rules of the decisional model, interrogating the indicators for the crop schedule and the state of the system (weather, soil, plant), and triggering actions when the stipulated conditions are fulfilled. Three types of result are possible:

- Synthetic yearly outputs. These outputs concern the actions taken after the application of the decision rules and their consequences for yield and some risks, including residual soil mineral nitrogen content after harvest, an indicator of potential nitrate pollution.

- In addition to these standard outputs, users can construct their own output criteria. These criteria are defined in a 


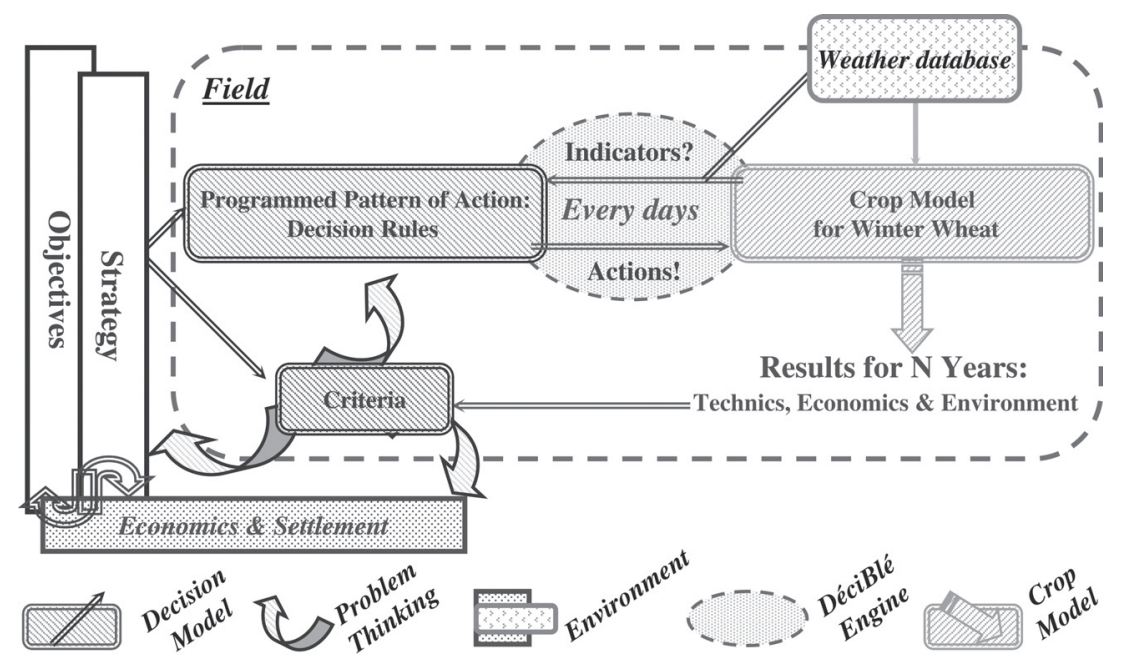

Figure 1. The principles of the DéciBlé model (Chatelin et al., 2005).

dedicated language, providing access to all of the variables calculated by the simulator.

- An agronomic diagnosis can be requested for a particular year (Doré et al., 1997). This analysis is based on comparisons of the levels of yield components reached with the technical management tested and with the technical management system giving the potential maximum yield.

\subsection{Formalisation of the design problem and choice of typical situations}

The specific problem analysed here, as stated in the introduction, is that of maintaining high wheat yield and grain quality whilst limiting the risks of nitrogen pollution. On the field scale, one way of limiting the risk of nitrogen pollution is to limit the amount of mineral nitrogen remaining in the soil after harvest - post-harvest nitrogen (PHN) - a PHN of 25 to $30 \mathrm{~kg} \cdot \mathrm{ha}^{-1}$ is sufficient for the critical concentration to be reached at the field outflow for $200 \mathrm{~mm}$ of drainage water. Such values are frequently reached after cereal crops in areas of intensive agriculture in the north of France (Mary et al., 1999). So, what crop management system should be recommended to limit PHN whilst ensuring sufficiently high levels of productivity in terms of quantity (grain yield) and quality (grain protein content)?

It is difficult for agronomists to provide an absolute answer to this question, because a large number of decisions concerning cropping practices are involved. The amounts of nitrogen supplied and taken up in the soil/crop system and the dynamics of these processes are directly involved and depend on decisions concerning cropping practices and soil nitrogen supply (Meynard et al., 1997). In France, the balance-sheet method can be used to calculate the total amount of nitrogen to be applied, as a function of estimated or measured soil nitrogen content (Rémy and Hébert, 1977). The influence of year-toyear variation in weather conditions must also be considered. A recent study (Gibbons et al., 2005) showed that weather con- ditions account for a larger proportion of variation in PHN than a wide range of techniques used in crop rotations. The exploration of a wide range of weather conditions is thus necessary to determine appropriate management strategies.

In accordance with the domain of validity of DéciBlé, we considered the problem of winter wheat crop management in the Paris Basin. We chose two field situations specific to this region, contrasting in soil nitrogen supplies due to the previous crop and in the amount of mineral nitrogen remaining in the soil at the end of winter, one of the main variables in the balance-sheet method. The "N-rich" field had a legume as the previous crop and high residual mineral nitrogen levels $\left(150 \mathrm{~kg} \cdot \mathrm{ha}^{-1}\right)$, whereas the "N-poor" field had sugar beet as the previous crop and low residual mineral nitrogen levels $\left(50 \mathrm{~kg} \cdot \mathrm{ha}^{-1}\right)$.

\section{RESULTS AND DISCUSSION}

We will first show how a multi-stage procedure for exploring the DéciBlé simulation model enabled an expert to generate appropriate technical management strategies, as described above. We then discuss the value and limitations of this approach.

\subsection{First stage: restriction of the decisional space and the choice of criteria}

The cropping decisions involved are those involving nitrogen supply and/or uptake. The total amount of nitrogen fertiliser applied over the crop cycle and the number of applications are clearly the first cropping decisions to be considered. Potential nitrogen uptake by the wheat crop depends on cultivar, plant density and sowing date (Meynard et al., 1997): it is therefore essential to take the decisions relating to these factors into account. Real nitrogen absorption by the crop, which determines final yield and the probable leaching of unabsorbed 
nitrogen, depends on the timing of applications with respect to certain stages of wheat development. If nitrogen application dates are not close enough to these optimal absorption stages, wheat yield is affected and nitrogen leaching increases PHN. The choice of dates for nitrogen applications with respect to wheat development stages is therefore of key importance.

Nitrogen absorption, loss and mobilisation in the grain also depend on decisions concerning other cropping practices, such as pest and disease control or tillage. We reduced the dimensions of the problem by making methodological choices as a function of three guiding factors: the decisional situations observed in practice in the Paris Basin, possible representations within DéciBlé and expert knowledge. Some cultural decisions, such as pest and disease control, which are badly simulated in DéciBlé, and the interaction between tillage and nitrogen dynamics, were not taken into account. Grain protein modelling in DéciBlé was considered unsatisfactory. This criterion was therefore considered by the agronomic expert solely in terms of the baking strength of the cultivar chosen.

We therefore explored decision rules for cultivar, sowing density, sowing date, and rates and dates of fertiliser nitrogen applications. For each variable, we defined a range to be explored based on the same three guiding factors. We chose 18 currently grown wheat cultivars for which all the necessary parameters for DéciBlé have been established. Given the constraints on arable farms in this region due to the organisation of work in the autumn (sugar beet and maize harvests before wheat sowing), we chose to explore a wide period of observed sowing dates, from October 1 to December 15. We considered two nitrogen applications - as regularly practised in this region - timed to coincide with the optimal developmental stages. For sowing density and maximum nitrogen rates for each application, we chose a range based on a combination of practical and agronomic knowledge: for example, sowing densities of less than 50 seeds per $\mathrm{m}^{2}$ would never be used in this region because the risks of poor emergence and winter frost cannot be counteracted by tillering rate. Table I summarises these choices restricting the decisional space to be explored.

Different output variables of the DéciBlé simulator originally guided our search for a solution. These output variables were yield, risk of nitrate pollution, level of nitrogen deficiency at the two key stages for nitrogen application (tillering and the " $1-\mathrm{cm}$ ear" stage) and the nitrogen requirements at these stages for achievement of the potential yield of each cultivar.

PHN was used as a basic indicator of the risk of nitrate pollution, and was expressed in two ways: the mean amount of $\mathrm{N}$ and the frequency with which a fixed threshold $\left(30 \mathrm{~kg} \cdot \mathrm{ha}^{-1}\right)$ was exceeded over a series of climatic years. PHN simulation in DéciBlé has not been validated per se, but global validation of the simulator on yield and yield component criteria has been shown to be broadly satisfactory (see Chatelin et al., 2005), as has its simulation of nitrogen supplies and absorption. We thus consider PHN simulation to be within about $10 \%$ of actual values.

We then evaluated the acceptability of solutions in terms of the two chosen objectives: yield, taking a minimum objective yield of 9 tha $^{-1}$ and an average yield of 10 tha $^{-1}$, and the frequency of the PHN values exceeding the $30 \mathrm{~kg} \cdot \mathrm{ha}^{-1}$ threshold. We also included the choice of cultivar, in terms of baking quality, to guide the search for solutions.

\subsection{Second stage: choice of a subgroup of cultivars in the chosen field situations}

We systematically explored the behaviour of each cultivar with "management to potential", corresponding to an absence of nitrogen and water restriction and assuming the control of pests and diseases, over the whole possible sowing period. The objective here was to limit the number of candidate cultivars for subsequent studies of other decisions: we assumed a sowing density of 200 seeds. $\mathrm{m}^{-2}$ : nitrogen application dates were fixed strictly according to optimal development stages (tillering and " $1-\mathrm{cm}$ ear"), and rates were calculated annually to ensure that the potential requirements of the plant on the date of application were satisfied. Simulations were done for 20 climatic years recorded at a meteorological station representative of the study zone. Six output variables were used to guide the expert's selection work. The first five of these variables were annual means (yield, sum of two applications, first application and PHN). The final variable was the frequency with which the $30 \mathrm{~kg} \cdot \mathrm{ha}^{-1}$ PHN threshold was exceeded. An example of the results (annual mean PHN for N-rich conditions) is provided in Table II for each cultivar and sowing date (results for five-day intervals).

In N-rich conditions, yield was the first sorting key used. Use of the $10 \mathrm{t}^{\mathrm{ha}} \mathrm{a}^{-1}$ criterion resulted in the elimination of nine cultivars. Another two cultivars were excluded due to their high PHN level, regardless of sowing date, and two very different cultivars were finally retained by the expert: Soissons, as a productive cultivar with good baking quality, representative of the cultivars recommended by development services, and Artaban as a possible alternative because of its low nitrogen requirements and lower but nonetheless acceptable baking quality.

In low-N conditions, the selection of other cultivars generally gave no satisfactory solution, whatever the output variables used: the difficulty of combining high yields with a low risk of pollution accounted for this situation. We rarely obtained PHN values below the $30 \mathrm{~kg} \cdot \mathrm{ha}^{-1}$ threshold, even when fertilisation was strictly limited to the crop requirements. This may appear non-intuitive, but it was necessary to apply large amounts of fertiliser to obtain high yields in soils with low levels of $\mathrm{N}$, resulting in larger amounts of unused fertiliser (due to degraded soil structure, leaching following heavy rain or differences between application dates and the dynamics of uptake by the crop).

However, one cultivar, Artaban, stood out as the most favourable in terms of PHN values and nitrogen requirements in low-N conditions. Furthermore, this cultivar gave sufficiently high yields in these conditions. We therefore decided to retain this cultivar, together with Soissons, for both field situations.

The amounts of nitrogen applied in the simulation were the second element of choice at this stage. The recommended first 
Table I. Restriction of the decisional space.

\begin{tabular}{l|ll} 
Decisional stage & Decision & Range chosen for each decision \\
\hline \multirow{2}{*}{ Sowing } & Cultivar & 18 different cultivars \\
& Density & {$[50,350]$ seeds.m- } \\
& \\
\hline \multirow{2}{*}{ 1st nitrogen application } & Date & Centred on the tillering stage $[-20,+15]$ days \\
& Rate & {$[0,150] \mathrm{kg} \cdot \mathrm{ha}^{-1}$} \\
\hline 2nd nitrogen application & Date & Centred on the 1-cm ear stage $[-20,+15]$ days \\
& Rate & {$[0,200] \mathrm{kg}^{-1} \mathrm{ha}^{-1}$} \\
\hline
\end{tabular}

Table II. Mean Post-Harvest Nitrogen (PHN) by cultivar and sowing date (managed to potential, N-rich conditions).

\begin{tabular}{|c|c|c|c|c|c|c|c|c|c|c|c|c|c|c|c|c|}
\hline $\begin{array}{l}\text { Sowing date } \\
\text { Cultivar }\end{array}$ & & & 0 & $1 / 10$ & /10 & & 10 & & & & & & & & & \\
\hline APPOLO & & 21.2 & 22 & 22.1 & 23.9 & 23.6 & 24.8 & 29.8 & 32.8 & 33.1 & 33.2 & 33.5 & 34.2 & 40.8 & 40.8 & 41.5 \\
\hline ARMINDA & $¥$ & 21.2 & 21.4 & 21.4 & 23.4 & 23.4 & 24.4 & 29 & 32 & 32 & 32.4 & 34.4 & 33.5 & 35.2 & 35.6 & 37.1 \\
\hline OSSIN & PHA & 36.1 & 36 & 37.8 & 39.4 & 38.8 & 38.8 & 41.9 & 43 & 43 & 42.9 & 42.2 & 42.9 & 43.4 & 43.2 & 59.6 \\
\hline ER & & 21.2 & 20.9 & 21.1 & 3.6 & 23.4 & 5 & .9 & 34.8 & 4.9 & 8 & .9 & 9 & 39.8 & 9.8 & 41.1 \\
\hline BAROUPEUR & $¥$ & 22.6 & 22.9 & 23.2 & 24.4 & 24.4 & 24.8 & 28 & 30.4 & 30.2 & 30.4 & 30.1 & 30.8 & 31.6 & 32.4 & 33.4 \\
\hline BEAUCHАMP & $¥$ & 22.4 & 22.6 & 23.2 & 24.1 & 23.8 & 24.9 & 28 & 29.9 & 29.8 & 29.6 & 29.4 & 29.6 & $3 \theta$ & 30 & 31.4 \\
\hline GENHAL & $¥$ & 22.4 & 22.6 & 23.2 & 24.8 & 24.5 & 25.6 & 31 & 34.4 & 34.4 & 34.9 & 34.9 & 41.6 & 42.9 & 43.4 & 44.2 \\
\hline PROMENTIN & $¥$ & 22.4 & 22.6 & 23.2 & 24.2 & 24.4 & 25.2 & 29.4 & 32.4 & 32 & 32.4 & 32.2 & 37 & 38.1 & 38 & 39.2 \\
\hline THESEE & & 22.6 & 22.9 & 23.2 & 24.5 & 24.6 & 25 & 29.1 & 32 & 32.1 & 32 & 32 & 32.9 & 34.2 & 34.5 & 35.9 \\
\hline ARTABAN & & 23.5 & 23.5 & 23.6 & 24.4 & 24.6 & 25.6 & 29.1 & 30.5 & 30.1 & 29.9 & 29.8 & 30.2 & 30.8 & 30.6 & 31.6 \\
\hline FORTAL & $¥$ & 23.4 & 23.4 & 23.4 & 24.5 & 24.8 & 25.6 & 28.5 & 30.1 & 30.2 & 30.2 & 30.2 & 34 & 32 & 32.4 & 33.4 \\
\hline РАСТОLЕ & $¥$ & 23.4 & 23.1 & 23.1 & 24.5 & 24.4 & 25.4 & 28.2 & 29.9 & $3 \theta$ & 29.8 & 29.5 & 29.9 & 30.6 & 31 & 32 \\
\hline SCIPION & & 23.5 & 23.5 & 23.6 & 24.4 & 24.6 & 25.8 & 29.2 & 30.9 & 30.9 & 30.9 & 31.1 & 32 & 33 & 33.4 & 34.9 \\
\hline SIDERAL & & 23.5 & 23.4 & 23.8 & 25.5 & 25.4 & 26.5 & 31.4 & 34.4 & 34.4 & 34.5 & 34.5 & 35.6 & 37.4 & 37.5 & 38.9 \\
\hline SOISSONS & & 23.8 & 23.1 & 23.4 & 25.9 & 26.1 & 27.1 & 34.1 & 38.6 & 38.6 & 38.9 & 38.9 & 40 & 42.4 & 42.8 & 43.6 \\
\hline TALENT & $¥$ & 23.9 & 23.5 & 24 & 24.8 & 25.1 & 25.9 & 29.1 & 30.6 & 30.8 & 30.6 & 30.8 & 31.2 & 32.5 & 32.8 & 34.1 \\
\hline FIDEL & $¥$ & 23.2 & 23.4 & 24 & 24.9 & 24.9 & 25.9 & 28.8 & 30.6 & 30.6 & 30 & 29.5 & 30.4 & 30.8 & 34 & 32 \\
\hline RECHTAI & PHA & 46.5 & 44 & 42.6 & 43.9 & 43 & 42.5 & 44.6 & 46.2 & 45.8 & 45.8 & 45.4 & 45.6 & 46.2 & 46.1 & 46.9 \\
\hline
\end{tabular}

Legend: RECITAI = an eliminated cultivar; criteria $\mathrm{Y}=$ yield, $\mathrm{PHN}=$ post-harvest nitrogen, $¥=$ yield level justifies elimination of the cultivar, $\mathrm{PHA}=$ the high level of PHN justifies elimination of the cultivar.

application varied little according to sowing date in either set of conditions, regardless of the cultivar used. In N-rich conditions the rates applied were very low, below $5 \mathrm{~kg} \cdot \mathrm{ha}^{-1}$. In $\mathrm{N}$-poor conditions, they fluctuated around $40 \mathrm{~kg} \cdot \mathrm{ha}^{-1}$.

These results were used directly to guide the next systematic exploration: they suggested that the first application should be abandoned in N-rich conditions and that a single dose of 40-50 kg.ha ${ }^{-1}$ should be applied in N-poor conditions. Eliminating early application in N-rich conditions would represent a major change to usual practice.

This stage turned out to be crucial from both the methodological and technical points of view. Methodologically, it allowed us to adapt and formalise the problem. This resulted in a compromise between enlargement and simplification in the structuring of the set of strategies to be considered and to reduce the size of the problem to be resolved.

\subsection{Third stage: generation of technical management strategies by cultivar and $\mathrm{N}$ conditions}

The two selected cultivars were then combined with the two field situations. Yield and the frequency with which the $30 \mathrm{~kg} \cdot \mathrm{ha}^{-1}$ PHN threshold was exceeded were maintained as the criteria on which solutions were based.

The previous stage fixed sowing density and generated a simple decision rule for the first $\mathrm{N}$ application: no $\mathrm{N}$ applied to the N-rich field and an application rate of $40 \mathrm{~kg} \cdot \mathrm{ha}^{-1}$ for the $\mathrm{N}$-poor field, regardless of sowing date and cultivar. Based on these decisions, we carried out simulations for sowing date and amount and date of the second $\mathrm{N}$ application. For the sake of simplicity, we present here only results for the amount of nitrogen applied at the optimal agronomic stage ("1-cm ear").

Figures 2 and 3 show simulation runs combining sowing dates ( $\mathrm{x}$ axis, from 1 October until 10 December, with increments of 5 days) and the amount of $\mathrm{N}$ applied at the second 

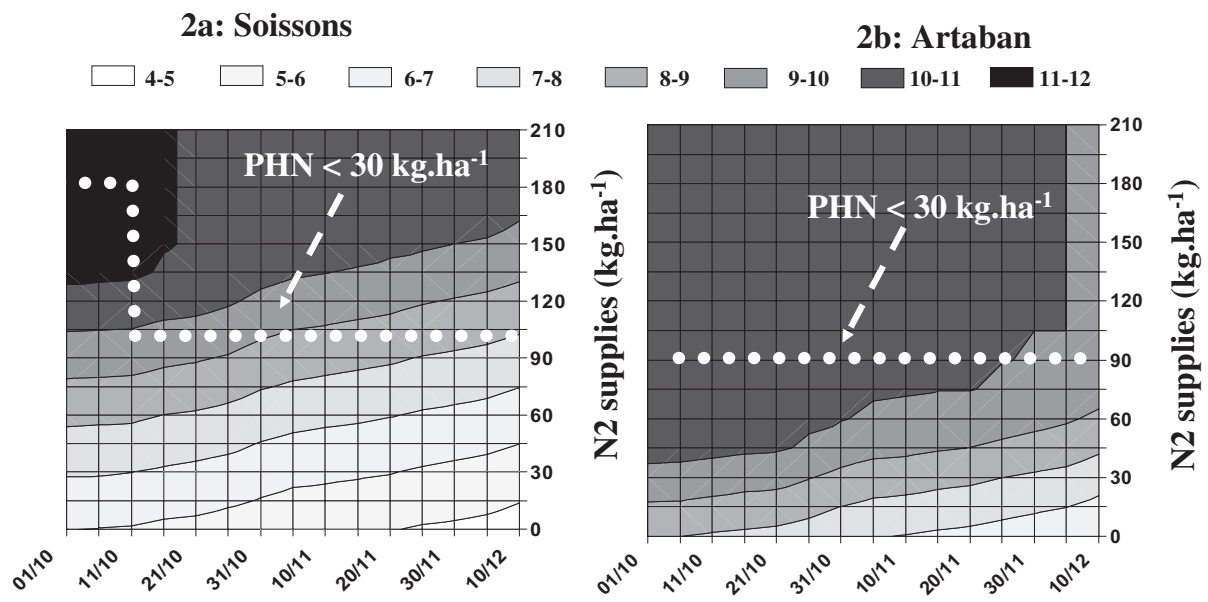

Sowing dates

Figure 2. Mean yield (t.ha $\left.{ }^{-1}\right)$, shaded and Post-Harvest Nitrogen envelope curve $\left(\mathrm{PHN}<30 \mathrm{~kg}^{-h a^{-1}}\right)$ for "N-rich conditions". Legend: Yield (grey shading) in t.ha ${ }^{-1}, \mathrm{PHN}=$ post-harvest nitrogen in $\mathrm{kg} \cdot \mathrm{ha}^{-1}$.

application time (y axis, from 0 to $210 \mathrm{~kg} \cdot \mathrm{ha}^{-1}$, increments of $15 \mathrm{~kg} \cdot \mathrm{ha}^{-1}$ ). The two criteria studied (yield and frequency with which the $30 \mathrm{~kg} \cdot \mathrm{ha}^{-1}$ PHN threshold was exceeded) constitute the third axis. Yield is shown on the $\mathrm{z}$ axis, graded in shades of grey. Rates of $\mathrm{N}$ supply resulting in a PHN $<30 \mathrm{~kg} \cdot \mathrm{ha}^{-1}$ every year are shown as a dotted line.

The results for N-rich conditions are shown in Figure 2 for Soissons (2a) and Artaban (2b).

For Soissons (Fig. 2a), it was possible to achieve a PHN below $30 \mathrm{~kg} \cdot \mathrm{ha}^{-1}$ and a high yield (above $10 \mathrm{t}^{\mathrm{h}} \mathrm{ha}^{-1}$ ) if the crop was sown early (1st to 11 th October) and large amounts of nitrogen were applied (between 130 and $180 \mathrm{~kg}^{-h^{-1}}{ }^{-1}$. In the second sowing period (from 11th October - November) PHN could only be kept below $30 \mathrm{~kg} \cdot \mathrm{ha}^{-1}$ by accepting a yield between 9 and 10 t.ha $^{-1}$, with $105 \mathrm{~kg}$ ha $^{-1}$ of applied nitrogen. Lastly, no solution was found for later sowing dates, as the PHN was always above the $30 \mathrm{~kg} \cdot \mathrm{ha}^{-1}$ threshold if attempts were made to achieve a yield of more than 9 t.ha $^{-1}$.

For Artaban (Fig. 2b), a satisfactory solution was obtained (yield $>10$ t.ha $^{-1}$ and PHN $<30 \mathrm{~kg} \cdot \mathrm{ha}^{-1}$ every year) for all sowing dates between 1st October and 30th November, covering most of the sowing period. This solution was obtained with $\mathrm{N}$ rates below those required for Soissons $\left(90 \mathrm{~kg} \cdot \mathrm{ha}^{-1}\right)$. For very late sowing dates (December), PHN values below $30 \mathrm{~kg} \cdot \mathrm{ha}^{-1}$ units could only be achieved by accepting yields between 9 and 10 t.ha $^{-1}$.

Thus, if we accept all yields above 9 t.ha $^{-1}$ as satisfactory, then both cultivars satisfied both criteria at the beginning of the sowing period, until 11th October, with higher yields obtained for Soissons provided a larger amount of nitrogen was applied. From 11th October to 5th November, Artaban was superior to Soissons, as it gave a satisfactory yield with a limited second application of nitrogen. For later sowings, only Artaban satisfied both criteria. The proposed decision rules based on these data are shown in Table III.
These rules can be expressed as the following propositions: "if sowing before or on 5th November, the choice of cultivar is unimportant unless you wish to limit the amount of nitrogen applied, in which case Artaban should be chosen. For later sowing dates, Artaban should be chosen".

Satisfactory yields were not obtained by maintaining PHN $<30$ kg.ha ${ }^{-1}$ every year: around 5 t.ha $^{-1}$ for Soissons and 6 t.ha ${ }^{-1}$ for Artaban. A possible compromise was to accept a frequency of two years in which PHN exceeded $30 \mathrm{~kg} \cdot \mathrm{ha}^{-1}$ (Fig. 3).

For Soissons, this relaxation of the constraint was not sufficient for the desired yield to be achieved, so this variety could not be chosen. For Artaban, a yield higher than 9 t.ha $^{-1}$ was achieved for sowings up to 1st November, with a nitrogen application rate of between 135 and $165 \mathrm{~kg}^{-h^{-1}}$. For later sowings, Artaban gave a yield of 8 to 9 t.ha $^{-1}$, versus 6 to 7 tha $^{-1}$ for Soissons, with a nitrogen application rate of $120 \mathrm{~kg} \cdot \mathrm{ha}^{-1}$.

Thus, in N-poor conditions, the deduced rule could be summarised as "sow a cultivar of the Artaban type whatever the sowing date; apply $40 \mathrm{~kg} \cdot \mathrm{ha}^{-1} \mathrm{~N}$ at the end of the tillering stage and modify the amount of $\mathrm{N}$ for the second application as a function of sowing date: between $165 \mathrm{~kg} \cdot \mathrm{ha}^{-1}$ and $120 \mathrm{~kg}$.ha ${ }^{-1}$, with a decrease of $15 \mathrm{~kg} \cdot \mathrm{ha}^{-1}$ for every 10 days of delay in sowing".

\subsection{Discussion: value and limitation of this method}

Exploration with a simulation tool made it possible to find acceptable solutions to a complex problem, generating suitable decision rules that could subsequently be tested experimentally. The use of simulations instead of, or before, experiments is not specific to this study: Jones et al. (2003) demonstrated the use of decision support systems, such as DSSAT, not to help farmers make decisions but to improve decisions about transferring production technology from one location to others 
Table III. Proposed decision rules for N-rich conditions.

\begin{tabular}{|c|c|c|c|c|}
\hline \multirow[t]{3}{*}{ Sowing period } & \multirow{3}{*}{ Cultivar } & Expected mean & \multicolumn{2}{|c|}{ Nitrogen application around stage $\left(\mathrm{kg} \cdot \mathrm{ha}^{-1}\right)$} \\
\hline & & yield $\left(\right.$ t.ha $\left.^{-1}\right)$ & & \\
\hline & & & tillering & 1-cm ear \\
\hline \multirow[t]{2}{*}{ 1-11 October } & Soissons & $\geqslant 11$ & 30 & $150 *$ \\
\hline & Artaban & $\geqslant 10$ & 0 & 90 \\
\hline \multirow[t]{2}{*}{11 October-5 November } & Artaban & $\geqslant 10$ & 0 & 90 \\
\hline & Soissons & $\geqslant 9$ & 0 & 105 \\
\hline After 5 November & Artaban & $\geqslant 9$ & 0 & 90 \\
\hline
\end{tabular}

*: Applications of more than $150 \mathrm{~kg} /$ ha were split into two doses. The use of such high doses is inadvisable (risk of leaf scorch, machinery unsuitable for liquid application, etc.)

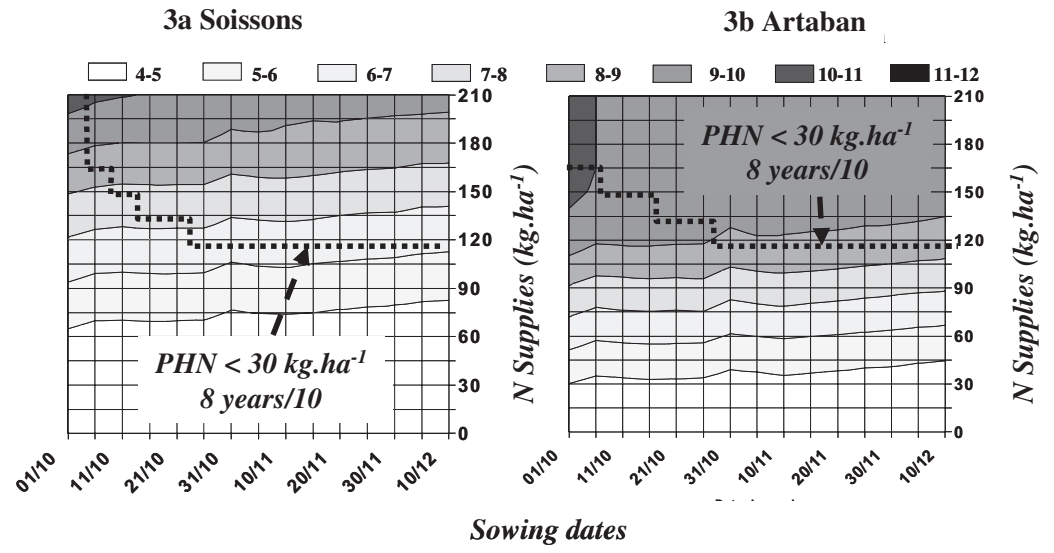

Figure 3. Mean yield (t.ha $\left.{ }^{-1}\right)$, shaded and Post-Harvest Nitrogen envelope curve (PHN $\left.<30 \mathrm{~kg} \cdot \mathrm{ha}^{-1}\right)$ for 8 of 10 years for "N-poor conditions". Legend: Yield (shaded grey) in t.ha ${ }^{-1}, \mathrm{PHN}=$ post-harvest nitrogen in $\mathrm{kg} \cdot \mathrm{ha}^{-1}$.

with different soil and climate conditions, from a research perspective. The use of crop models to support decision-making for research and teaching was highlighted by Van Ittersum et al. (2003), who stressed in particular the use of such models for designing experiments, testing hypotheses and generating new research questions. In Washington State, Peralta and Stöckle (2001) used the CropSyst simulator (Stöckle et al., 2003) to study the dynamics of nitrate leaching in an irrigated potato rotation: they noted the importance of the crop-free period on nitrate leaching and concluded that the rates of nitrogen fertiliser application should be reduced. However, they did not design fertilisation strategies and compare them with predetermined fertiliser application rates.

Our model-based experimentation is also research- and advice-oriented, but includes an explicit representation of "farmer-like" decision-making. This approach is made possible by the strong coupling between the decisional and biotechnical models of the DéciBlé simulator. The DéciBlé biotechnical model has several limitations and should be improved and updated. However, the original structure of the simulator and the explicit nature of the decision rules make such exploration possible. In principle, other simulators containing a decisional module, such as the APSIM model (Olesen et al., 1997; Keating et al., 2003), could also be used. The use of simulation models for decision-making support and learning processes is a new area for the designers of crop models (Van Ittersum et al., 2003). McCown (2002) recommended making decision support systems (DSS) function as a mimeomorphic "proxy" of the managers' decision-making process, chiefly for strategic planning decisions, and using these systems more for learning than for design, to make it easier for managers to use these systems correctly. What is true for managers (in this case, farmers) would also seem to apply to researchers and advisers: the simulator can be used to "learn" and generate new ideas and questions. With this aim in mind, we created a specific methodology, interfacing expert knowledge with simulator use.

Our step-by-step procedure made it possible to resolve this problem. This exploration methodology aims to decrease the dimensions of the problem progressively, by combining expert knowledge of situations, adaptation to the strengths and weaknesses of the simulation tool and the simulations themselves. 
The work presented here is original and interesting in three respects:

- It takes into account opposing criteria for judging strategies of technical management, without reducing them to a single synthesis criterion, as is often the case in approaches to multi-criterion optimisation.

- It devises strategies in the form of realistic action plans expressed as decision rules of a type that farmers can implement.

- Uncertainty is dealt with by taking into account weather variability in both the translation of decision rules into technical actions for a given season and the results of these actions.

The proposed systematic exploration methodology should be suitable for other similar design problems, but is likely to reach its limits for more complex conceptual problems in which it is not easy to define small decisional spaces. We will therefore need to use methods for optimisation by simulation, to find optimal solutions to complex problems using a simulation model alone (Ólafsson and Kim, 2002). For example, the hierarchical optimisation method $\mathrm{P} 2 \mathrm{P}$ was developed for the design of complex irrigation protocols defined by experts, through the use of the MODERATO simulation model of maize crop management (Bergez et al., 2004).

In cases in which it is difficult, even for agronomic experts, to define a set of variables for optimisation, methods derived from artificial intelligence, such as genetic algorithms or reinforcement learning (Sutton and Barto, 1998; Garcia et al., 2001), may be used. These methods may automatically generate near-optimal decision rules for the criterion considered. These methods have been used with the DéciBlé simulator, to resolve problems similar to that presented here (Garcia, 1999; Ndiaye, 1999; Garcia et al., 2001).

These optimisation or artificial intelligence methods can generally deal with only one objective at a time, limiting their suitability for the type of exploration by simulation approach we propose here. However, recent advances in multi-objective simulation-based optimisation (Eskandari et al., 2005) could lead to the development of new approaches coupling exploration by simulation and optimisation for large, complex multi-criterion design problems.

\section{CONCLUSION}

The systematic exploration by simulation method presented here generated acceptable solutions to a complex design problem for wheat management. This step-by-step approach leads to progressive limitation of the domain to be explored. It is based on a simulation tool combining decisional and biotechnical models.

Some of the solutions obtained were not entirely intuitive, such as elimination of the first $\mathrm{N}$ application, the good fit of Artaban to the objectives, and behaviour in N-poor conditions. However, these solutions seem to be realistic and easy to translate into decision rules for wheat technical management. The objective of using simulation to limit the number of situations required for field experimentation was achieved: we identified five cases in $\mathrm{N}$-rich conditions and two in $\mathrm{N}$-poor conditions for which field experimentation remained necessary to confirm the simulated results.

With the requirements of sustainable agriculture, crop management techniques will increasingly need to be modified to attain several goals at once, including environmental and economic goals. The complexity of the context is thus increasing. This could lead to an explosion of demand for experimentation, which would be impossible to satisfy. The rationalisation of field experimentation is therefore of prime importance. Moreover, field experimentation should increasingly involve the dissemination of complete strategies to farmers, rather than the design of isolated operations.

Advisers and researchers therefore need to develop "thinking support systems" to design these new technical strategies as a function of farmers' objectives and decision rules. Exploration by simulation, with tools such as Déciblé, is one possible way of generating technical management plans expressed as decision rules. This type of research could open up new opportunities for model makers in the domain of agronomy.

\section{REFERENCES}

Attonaty J.M., Chatelin M.H., Garcia F. (1999) Interactive simulation modelling in farm decision making, Comput. Electron. Agr. 22, $157-170$.

Aubry C., Papy F., Capillon A. (1998) Modelling decision-making processes for annual crop management, Agr. Syst. 56, 45-65.

Bergez J.E., Garcia F., Lapasse L. (2004) A hierarchical partitioning method for optimizing irrigation strategies, Agr. Syst. 80, 235-253.

Carberry P.S., Hochmann Z., McCown R.L. (2002) The FARMSCAPE approach to decision support: farmers', advisers', researchers' monitoring, simulation, communication and performance, evaluation, Agr. Syst. 74, 141-177.

Chatelin M.H., Aubry C., Leroy P., Papy F., Poussin J.C. (1993) Pilotage de la production et aide à la décision stratégique, Cah. Économie Sociologie Rurales 28, 119-138.

Chatelin M.H., Aubry C., Poussin J.C., Meynard J.M., Massé J., Verjux N., Gate Ph., Le Bris X. (2005) DéciBlé, a software package for wheat crop management simulation, Agr. Syst. 83, 77-99.

Cox P.G. (1996) Some issues in the design of agricultural Decision Support Systems, Agr. Syst. 52, 355-381.

Cros M.J., Duru M., Garcia F., Martin-Clouaire R. (2004) Simulating management strategies: the rotational grazing example, Agr. Syst. $80,23-42$.

Doré T., Sebillotte M., Meynard J.M. (1997) A diagnostic method for assessing regional variations in crop yield, Agr. Syst. 54, 169-188.

Eskandari H., Rabelo L., Mollaghasemi M. (2005) Multiobjective simulation optimization using an enhanced genetic algorithm, in: Kuhl M.E., Steiger N.M. Armstrong F.B. and Joines J.A. (Eds.), Proceedings of 2005 Winter Simulation Conference, pp. 833-841, Orlando, Florida, USA, December 4-7, 2005.

Garcia F. (1999) Use of reinforcement learning and simulation to optimise wheat crop technical management. In Proceedings of the International Congress on Modelling and Simulation (MODSIM'99) Hamilton, New-Zealand, pp. 801-806. 
Garcia F., Martin-Clouaire R., Nguyen L.G. (2001) Generating decision rules by reinforcement learning for a class of crop management problems, Proceedings of the 3rd European Conference of the European Federation for Information Technology in Agriculture, Food and the Environment (EFITA'01), in: Steffe J. (Ed.), Montpellier, June 2001.

Gibbons J.M., Sparkes D.L, Wilson P., Ramsden S.J. (2005) Modelling optimal strategies for decreasing nitrate loss with variation in weather - a farm-level approach, Agr. Syst. 83, 113-134.

Hammer G.L., Kropff, M.R., Sinclair T.R., Porter J.R. (2002) Future contributions of crop modelling - from heuristics and supporting decision making to understanding genetic regulation and aiding crop improvement, Eur. J. Agron 17, 15-31.

Jones J.W.W., Hoogenboom G., Porter C.H., Boote K.J., Batchelor W.D., Hunt L.A., Wilkens P.W., Singh U., Gijsman A.J., Ritchie J.T. (2003) The DSSAT cropping system model, Eur. J. Agron. 18, 235265.

Keating B.A., Carberry P.S., Hammer G.L., Probert M.E., Robertson M.J., Holzworth D., Huth N.I., Hargreaves J.N.G., Meinke H., Hochman Z., McLean G., Verbug K., Snow V., Dimes J.P., Silburn M., Wang E., Brown S., Bristow K.L., Asseng S., Chapman S., McCown, R.L., Freebairn D.M., Smith J.C. (2003) An overview of APSIM, a model designed for farming system simulation, Agr. Syst. 18, 267-288.

Lorino P. (1991) Le contrôle de gestion stratégique, la gestion par les activités, Dunod, Paris..

Loyce C., Rellier J.P., Meynard J.M. (2002) Management planning for winter wheat with multiple objectives (2): ethanol-wheat production, Agr. Syst. 72, 33-57.

Mary B., Beaudoin N., Justes E., Machet J.M. (1999) Calculation of nitrogen mineralization and leaching in fallow soils using a simple dynamic model, Eur. J. Soil Sci. 50, 1-18.

McCown R.L. (2002) Changing systems for supporting farmers' decisions: problems, paradigms, and prospects, Agr. Syst. 74, 179-220.
Meynard J.M., Justes E., Machet J.M., Recous S. (1997) Fertilisation azotée des cultures annuelles de plein champ, in: Maîtrise de l'azote dans les agrosystèmes, INRA "Les Colloques", Paris, 83, pp. 183-199.

Ndiaye S.M. (1999) Apprentissage par renforcement en horizon fini: Application à la génération de règles pour la conduite d'une culture, Thèse de l'Université Paul Sabatier, 263 p.

Ólafsson S., Kim J. (2002) Simulation optimization, Proceedings of the 2002 Winter Simulation Conference, in: Yücesan E., Chen C.-H., Snowdon J.L., Charnes J.M. (Eds.).

Olesen J.E., Pedersen L., Christensen S., Secher B.J.M., Petersen J. (1997) An integrated decision support system for management of winter wheat. First European Conference for Information Technology in Agriculture, Copenhagen, pp. 279-284.

Papy F. (1994) Working knowledge concerning technical systems and decision support. in: Dent J.B., McGregor M.J. (Eds), Rural and Farming Systems Analysis, European Perspectives. Cab International, Edimburgh, pp. 222-235.

Peralta J.M., Stöckle C.O. (2001) Dynamics of nitrate leaching under irrigated potato rotation in Washington State: a long-term simulation study, Agr. Ecosyst. Environ. 88, 23-34

Quéau P. (1986) Éloge de la simulation : de la vie des langages à la synthèse des images, Coédition Champ Vallon/INA, Paris.

Rémy J.C., Hébert, R. (1977) Le devenir des engrais azotés dans le sol, C.R. Acad. Agr. Fr. 63, 700-710.

Stöckle C.O., Donatelli M., Nelson R. (2003) CropSyst, a cropping system simulation model, Eur. J. Agron. 18, 289-307

Sutton R.S., Barto A.G. (1998) Reinforcement Learning, MIT Press, New York.

Van Ittersum M.K., Leffelaar P.A., Van Keulen H., Kropff M.J., Bastiaans L., Goudriaan J. (2003) On approaches and applications of the Wageningen crop models, Eur. J. Agron. 18, 201-234 